\title{
Influence of cutting parameters on mechanisms causing slug pulling
}

\author{
Alexander Kindsmüller ${ }^{1}\left(\mathbb{D} \cdot\right.$ Agnes Schrepfer $^{1} \cdot$ Jens Stahl ${ }^{1} \cdot$ Isabella Pätzold $^{1} \cdot$ Anian Nürnberger $^{1} \cdot$ Roland Golle $^{1}$. \\ Wolfram Volk ${ }^{1}$
}

Received: 26 February 2021 / Accepted: 12 May 2021 / Published online: 20 May 2021

(c) The Author(s) 2021

\begin{abstract}
Shear cutting is one of the most widely used manufacturing processes in the production of sheet metal components. The reasons for this are the high output volume combined with low costs per part. The profitability of this process is significantly influenced by the lifetime of the active elements and the occurrence of unexpected process disturbances. While there are already many publications on the former, there are only few examinations on the wide spread process disturbance of slug pulling, which describes the phenomenon where the cut-out part is pulled upwards again during the punch return stroke. In particular, the different forces on the slug that cause this phenomenon have not yet been measured individually and independently of one another in one single tool. Thus, a shear cutting tool was developed that enables the measurement of the individual forces on the slug depending on various process parameters. Following, single stroke experiments were carried out to determine these forces and establish relationships between the process parameters, the characteristics of the slug and the measured forces. Finally, the interaction of all partial forces depending on selected process parameters is discussed in order to classify the relevance of every single force with regard to the occurrence of slug pulling. This understanding of the process is necessary in order to make a well-founded decision when designing future tools or selecting available remedial measures to avoid slug pulling.
\end{abstract}

Keywords Slug pulling $\cdot$ Blanking $\cdot$ Force measurement $\cdot$ Adhesion $\cdot$ Vacuum $\cdot$ Burr clamping

\section{Introduction}

Shear cutting is a widely used industrial process for cutting sheet metal. The mechanical separation of workpieces is performed by two blades moving in opposite directions past each other without forming a shapeless matter [1]. A typical shear cutting tool consists of the three elements punch, die and blank holder and is shown in Fig. 1. The die clearance is the distance between the punch and the die, measured perpendicular to the direction of movement of the punch [1]. It is common to specify the die clearance $u$ as a percentage of the sheet thickness [2].

One current field of research in shear cutting is the improvement of the quality of the cut surface. This includes for example an increase of the clean-cut zone [4], burr-free

Alexander Kindsmüller

alexander.kindsmueller@utg.de

1 Institute of Metal Forming and Casting, Technical University of Munich, Walther-Meißner-Straße 4, 85748 Garching, Germany cutting [5] or improving the formability of the cut surface [6]. In addition, a robust and wear-minimized process is also in the focus of research in order to improve the economic efficiency of shear cutting. For example, Mucha and Jaworski [7] examine the abrasive and adhesive wear when cutting silicon steel sheets and Hohmann, Schatz and Groche [8] present a monitoring system for examining the development of wear using the punch force signal. Options for reducing wear include adapting the tool steel used [9], using a suitable coating for the punch or the die [10], adjusting the die clearance to the geometry of the cutting line [11] or the use of optimized cutting edge geometries to reduce contact pressure [12].

In addition to the often expectable tool wear, unpredictable process disturbances can disrupt the production process. These include the jamming of slugs in the die [13], punch breaking [14], mechanical tool damage or machine breakdown due to sliver formation when shear cutting aluminum [15] or slug pulling [16].

Slug pulling is one of the most common process disturbances during shear cutting of sheet metals, especially when 


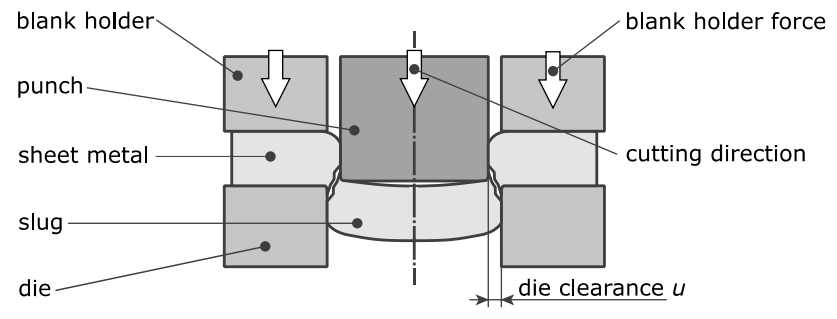

Fig. 1 Working principle of shear cutting according to [3]

using progressive dies. This phenomenon occurs when the cut-out part does not fall down as planned after the material has been separated, but is pulled upwards again by the punch and is usually finally stripped off on the lead frame. This can result in component defects due to jammed slugs in the lead frame or imprints on the components due to subsequent strokes, an obstruction of the belt feed or damage to the cutting tool. In addition, slug pulling is often associated with an interruption in production, which reduces the costeffectiveness of the manufacturing process. [16]

Slug pulling cannot be attributed to a single cause, but is caused by a combination of different mechanisms [17]. According to Tittel and Bernadic [16] slug pulling occurs if the sum of all forces responsible for slug sticking is greater than the sum of all forces responsible for slug removing. Forces responsible for slug sticking include a magnetic force, an adhesive force [18] and a vacuum force [19]. In addition, Dannenmann and Sugondo [20] were able to prove an additional force that causes slug sticking due to burr clamping. Forces responsible for slug removal include the gravitational force of the slug, a frictional force between the slug and the die and dynamic acceleration forces due to the cutting impact [16]. Figure 2 shows an overview of the forces that act on the slug after material separation.

To assess the risk of slug pulling, the causes and the interaction of the forces that cause slug sticking are to be examined in this work. These include the forces caused by adhesion, burr clamping and vacuum. Since magnetic force is strongly dependent on the treatment of the active elements used, for example on the magnetic clamping during

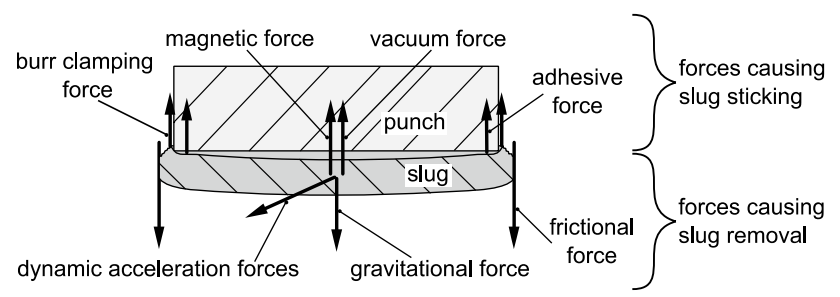

Fig. 2 Forces acting on the slug after material separation according to [16] and [20] the grinding process and the subsequent demagnetization, magnetic force is not considered in this work.

\section{Experimental setup}

To investigate the individual forces, an experimental shearcutting tool for cutting round holes with diameters of $10 \mathrm{~mm}$ and $20 \mathrm{~mm}$ is operated by servo-controlled modules of a stamping and forming machine (Fig. 3). The requirements placed on the forming machine are precise ram positioning with a high repeat accuracy as well as flexibly adjustable stroke height and cutting speed. Since very small forces are expected on the slug, high-precision sensors must be used and external interference must be shielded.

The shear-cutting tool has two different measurement configurations. The vacuum force is measured with a highly sensitive pressure sensor integrated in the punch, which is connected to the punch's front face via a drilled hole in the punch shaft (see Fig. 4a). The dead volume in the pressure sensor and in the drilled hole is about $2.2 \mathrm{~cm}^{3}$ due to the measurement setup. During the entire punch stroke, both the pressure signal and the punch position are monitored with the help of an additional position sensor. Here, the cutting direction is top-down, as is typical in industrial applications.

The adhesive force and the force caused by burr clamping are determined by measuring the push-off force, which is necessary to push the slug off the punch's front face. To do this, the cutting direction is changed to bottom-up. After the material has been separated, the punch is stopped at top dead centre whereby the slug remains on the punch's surface. In this position, the immersion depth of the punch into the die is so large that there is no longer any contact between the slug and the die. Subsequently, the slug is pushed off the punch's front face using a linear

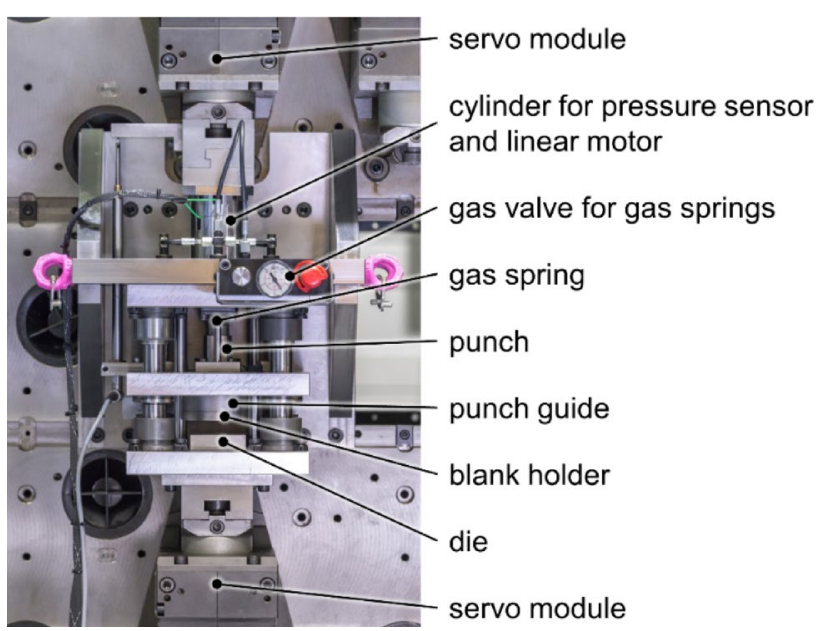

Fig. 3 Structure of the shear-cutting tool 


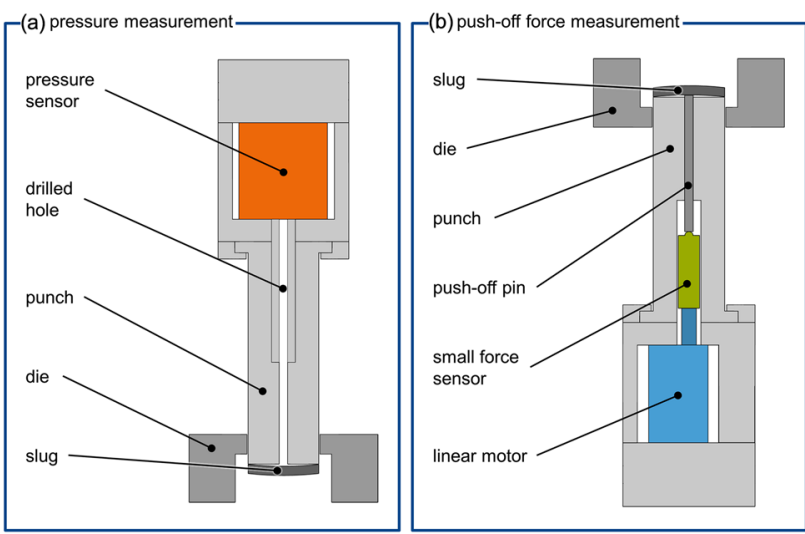

Fig. 4 Experimental setup for measuring the partial forces caused by vacuum, adhesion and burr clamping

Table 1 Investigated cutting and process parameters

\begin{tabular}{llll}
\hline Parameter & Symbol & Investigated magnitudes & Unit \\
\hline Punch diameter & $\varnothing$ & $10 ; 20$ & $\mathrm{~mm}$ \\
Relative die clearance & $u$ & $4.5,10.0,15.0,22.5$ & $\%$ \\
Punch-penetration-depth & $p p d$ & $0.5,2.0$ & $\mathrm{~mm}$ \\
Cutting edge radius & $r$ & 50,250 & $\mu \mathrm{m}$ \\
Lubrication & - & lubricant 1, lubricant 2, & - \\
& & w/o lubricant & \\
\hline
\end{tabular}

motor integrated in the punch and a push-off pin. A small force sensor with a measuring range between -20 and $200 \mathrm{~N}$ positioned between the linear motor and the pushoff pin records the push-off force (see Fig. 4b).

The burr height is determined according to [21] using a tactile surface measuring device. A probe tip is pulled over the surface, whereby the surface geometry in the vertical direction can be determined with a resolution of $0.38 \mu \mathrm{m}$ [22].

Table 1 gives an overview of the cutting and process parameters varied in this thesis. The parameters were chosen in such a way that, in addition to common die clearances of $10.0 \%$ and $15.0 \%$, the influence of very small or excessively large die clearances is also taken into account. The influence of the punch wear is considered by using different cutting edge radii representing the wear condition.

\section{Sheet metal material and lubrication}

The results presented in this work were achieved for shear cutting deep drawing steel DC03 with a sheet thickness of $1.0 \mathrm{~mm}$. DC03 is cold-rolled, unalloyed steel, which is characterized by its excellent cold formability. It is used, for
Table 2 Alloy composition of DC03

\begin{tabular}{lllllllll}
\hline & $\mathrm{C}$ & $\mathrm{Mn}$ & $\mathrm{P}$ & $\mathrm{S}$ & $\mathrm{Cr}$ & $\mathrm{Al}$ & $\mathrm{Cu}$ & $\mathrm{Fe}$ \\
\hline $\mathrm{wt} \%$ & 0.06 & 0.2 & 0.01 & 0.01 & 0.02 & 0.05 & 0.01 & Rest \\
\hline
\end{tabular}

Table 3 Typical mechanical material properties of DC03 (test direction transverse to rolling direction) [23]

\begin{tabular}{llll}
\hline & $\mathrm{R}_{\mathrm{e}}(\mathrm{MPa})$ & $\mathrm{R}_{\mathrm{m}}(\mathrm{MPa})$ & $\mathrm{A}_{80}(\%)$ \\
\hline $\mathrm{DC03}$ & 240 & $270-370$ & 34 \\
\hline
\end{tabular}

example, in the automotive industry as well as in general engineering sectors [23]. Below is an overview of the chemical composition and typical mechanical properties of this material (Tables 2, 3).

In addition to tests without lubricant, tests were also carried out with two lubricants with different viscosities. Lubricant 1 has a viscosity of $\nu=21 \mathrm{~mm}^{2} / \mathrm{s}$, a density of $\rho=0.85 \mathrm{~g} / \mathrm{cm}^{3}$ and is purely synthetic. It was developed for micro-spray technology and is suitable for minimal quantity lubrication. Lubricant 2 is based on mineral oil and has a viscosity of $\nu=4.1 \mathrm{~mm}^{2} / \mathrm{s}$ and a density of $\rho=0.83 \mathrm{~g} / \mathrm{cm}^{3}$. This lubricant is suitable for universal use and can therefore not only be used for shear cutting but also in forming or machining processes. Both lubricants were used without dilution.

\section{Measurement of the partial forces}

\subsection{Vacuum force}

\subsubsection{Test execution and evaluation}

During a complete punch stroke, both the air pressure curve on the punch's front face and the punch position are recorded. From this follows a typical air pressure curve for a punch-penetration-depth into the die of $2.0 \mathrm{~mm}$, which is presented in Fig. 5. This curve can be divided into six characteristic stages: In stage 1, the punch approaches the sheet metal surface, which results in an increase in air pressure. The slug is then bent by the bending moment that occurs during the shearing process [24], creating a vacuum pocket. This results in a pressure drop under the slug in the pressure curve (stage 2). The cutting impact due to the material separation causes a brief pressure oscillation (stage 3 ). In stage 4 the slug is pressed deeper into the die, whereby the vacuum generated in stage 2 is continuously reduced due to leaks between the slug and the punch's surface. When the bottom dead centre (BDC) is reached, there is almost no vacuum left. In stage 5 , a vacuum arises immediately during 
Fig. 5 Sketch of typical pressure curves when cutting DC03

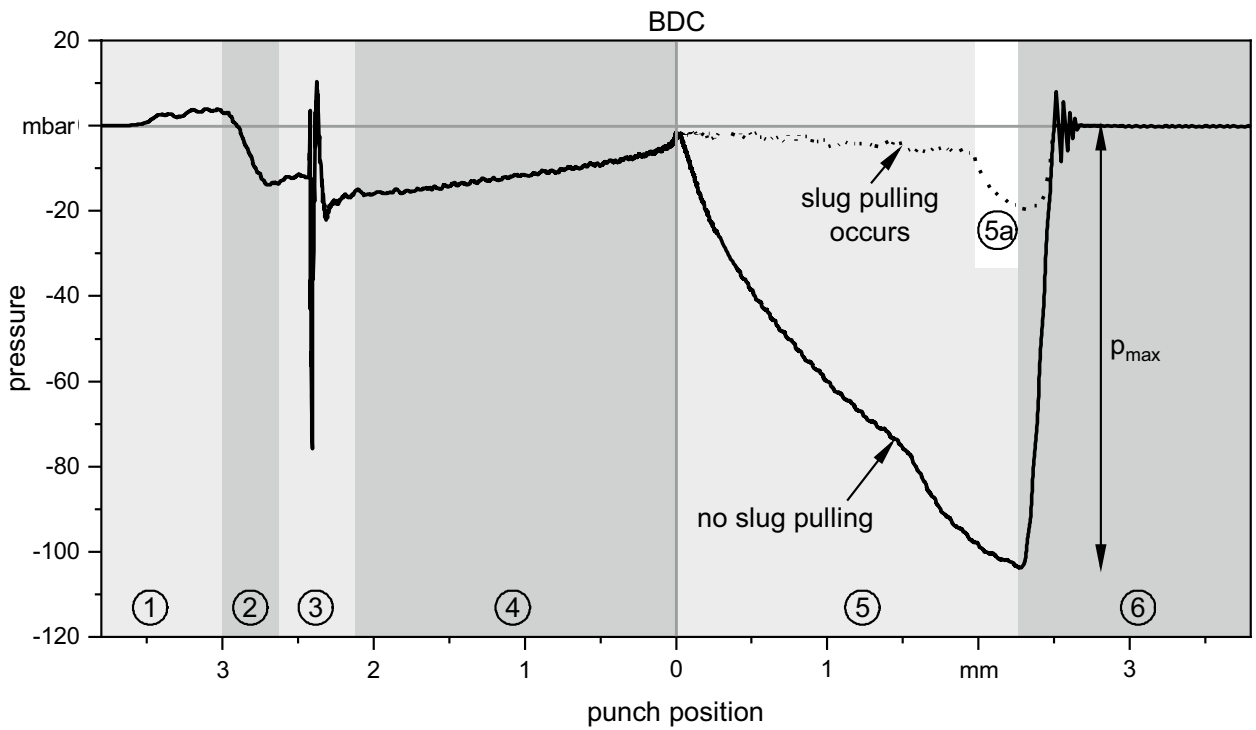

the punch return stroke if no slug pulling occurs. This is because the slug is stuck at the bottom dead centre while the punch return stroke leads to an increase in volume between the punch's front face and the slug. If slug pulling occurs, only a slight vacuum can be measured in stage 5 , since the slug does not remain stuck in the die channel and therefore no greater vacuum can build up. The vacuum only increases when the slug is stripped off from the punch by the lead frame in stage 5a. As soon as the punch is in the lead frame in stage 6 , the vacuum is quickly released. This can also be associated with slight air pressure oscillations.

To determine the vacuum force, the maximum vacuum measured during punch retraction at the end of stage 5 is used and multiplied by the surface area of the slug. Assuming the presence of a normal distribution of the measured values, the median value of the measurements is displayed in all the following figures. The error bar describes the range between the first and third quartiles.

\subsubsection{Results}

The influence of the relative die clearance $u$ and the punchpenetration-depth $p p d$ into the upper, cylindrical part of the die on the vacuum force is presented in Fig. 6. There is a trend with the vacuum force decreasing as the die clearance increases in both punch-penetration-depths. It also becomes apparent that higher vacuum forces are measured at the larger punch-penetration-depth of $2.0 \mathrm{~mm}$ in contrast to the $0.5 \mathrm{~mm}$ punch-penetration-depth. One reason for this can be found in the increase in volume between the punch and the slug during the punch return stroke, as this causes the vacuum. Since this volume enlarges with a

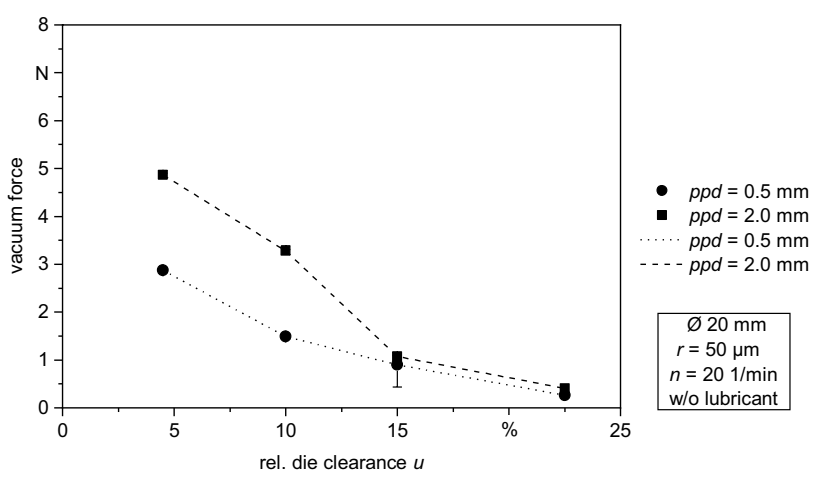

Fig. 6 Influence of the rel. die clearance $u$ and the punch-penetrationdepth $p p d$ on the vacuum force

greater punch-penetration-depth, higher vacuum forces are measured. The two measuring points with a punch-penetration-depth of $2.0 \mathrm{~mm}$ and at die clearances of $15 \%$ and $22.5 \%$ represent an anomaly. These two points are located at very low forces, since, unlike the other points, these cutting parameters caused slug pulling. Due to the large die clearances, the friction between the slug and the die is very low, which is why the slug is not stuck in the die but is pulled up again. This means that no greater vacuum force can be created without the slug moving up and the vacuum force being reduced again.

The largest vacuum force determined in Fig. 6 is for a relative die clearance of $4.5 \%$ and a punch penetration depth of $2.0 \mathrm{~mm}$ and is $4.87 \mathrm{~N}$; the lowest vacuum force is for a relative die clearance of $22.5 \%$ and a punch penetration depth of $0.5 \mathrm{~mm}$ and is $0.26 \mathrm{~N}$. By way of comparison: the 


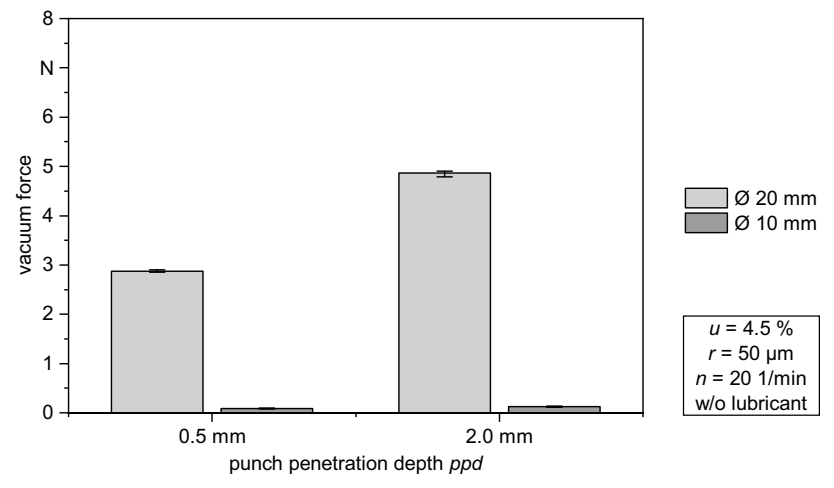

Fig. 7 Influence of the punch diameter on the vacuum force at different punch-penetration-depths

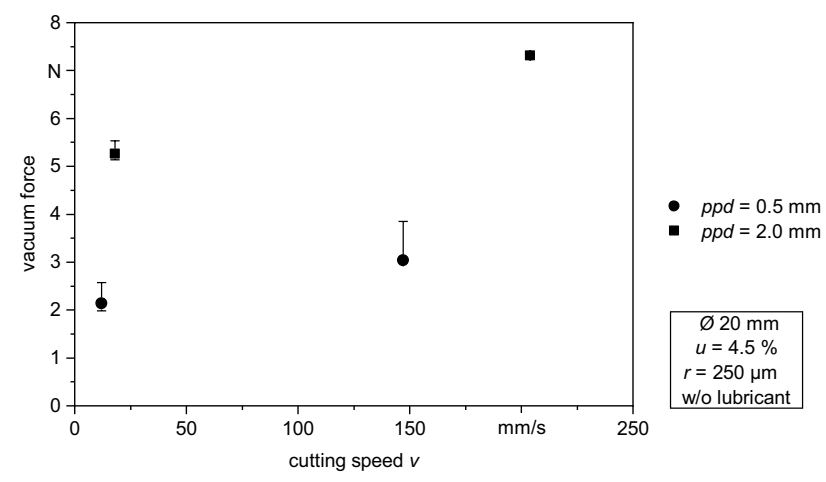

Fig. 8 Influence of the cutting speed on the vacuum force at differentpunch-penetration depths

gravitational force of a slug made of DC03 with a diameter of $20 \mathrm{~mm}$ is only $0.024 \mathrm{~N}(\varnothing 10 \mathrm{~mm}$ : $0.006 \mathrm{~N})$.

A comparison of the vacuum forces for different punch diameters shows that the vacuum force for punches with a diameter of $10 \mathrm{~mm}$ is significantly lower than for a diameter of $20 \mathrm{~mm}$ (see Fig. 7). One reason for this can be found in the relationship between the slug area and its circumference. While doubling the diameter quadruples the area of the slug, the circumference increases only by a factor of two. This is important because the vacuum is generated by the volume created between the slug and the punch during the return stroke, while it is reduced by the circular contact areas between the slug and the die and between the punch and the lead frame.

The dimension of the vacuum force depending on the cutting speed $v$ and the punch-penetration-depth $p p d$ is shown in Fig. 8. Here, the cutting speed $v$ is defined as the speed that prevails at the point the punch contacts the sheet metal. The vacuum force at the high cutting speeds is around 39\% higher at a punch-penetration-depth of $2.0 \mathrm{~mm}$ or around $57 \%$ higher at a punch-penetration-depth of
$0.5 \mathrm{~mm}$ compared to the vacuum force at reference speed. Since, in contrast to the previously considered cutting parameters, the increase in volume between the punch and the slug during the punch return stroke does not depend on the cutting speed, it is rather the reduction of the vacuum via leaks that is relevant for the resulting vacuum force. At high cutting speeds, the time available for reducing the vacuum is shorter than at slow cutting speeds, which results in higher vacuum forces. The reference speed is $12 \mathrm{~mm} / \mathrm{s}$ at a punch-penetration-depth of $0.5 \mathrm{~mm}$ and $18 \mathrm{~mm} / \mathrm{s}$ at a punch-penetration-depth of $2.0 \mathrm{~mm}$ and is the speed that results at a stroke rate $n$ of $201 / \mathrm{min}$. This stroke rate is roughly comparable to the stroke rate used in transfer presses for the production of large automobile body components, which is around $151 / \mathrm{min}$ [25]. The different cutting speeds despite the same stroke rate $n$ result from the sinusoidal stroke curve, which is why the punch has a higher impact speed on the sheet metal with a greater punch-penetration-depth.

\subsection{Burr clamping force}

\subsubsection{Test execution and evaluation}

The force caused by burr clamping is determined by measuring the push-off force, which is necessary to push the slug off the punch's front face after the material has been separated. To avoid any effects due to adhesion, the material is shear cut without lubricant. The push-off force measured is a combination of the following partial forces:

- Gravitational force of the slug

- Acceleration force due to the accelerated mass of the slug while pushing-off

- Burr clamping force

- Magnetic forces if there is residual magnetism in the punch or the slug

In addition, reference measurements of the push-off force are carried out, where the corresponding slug is placed on the punch manually without lubricant and with the burr removed beforehand. Since this measurement only determines the gravitational force of the slug, the acceleration force and any magnetic forces that may occur, the burr clamping force can be determined from the difference between the initial pull-off force measurement and the reference measurement. This procedure is illustrated in Fig. 9. In the following figures, the median value of the burr clamping force is displayed. The error bar describes the range between the first and third quartiles. 


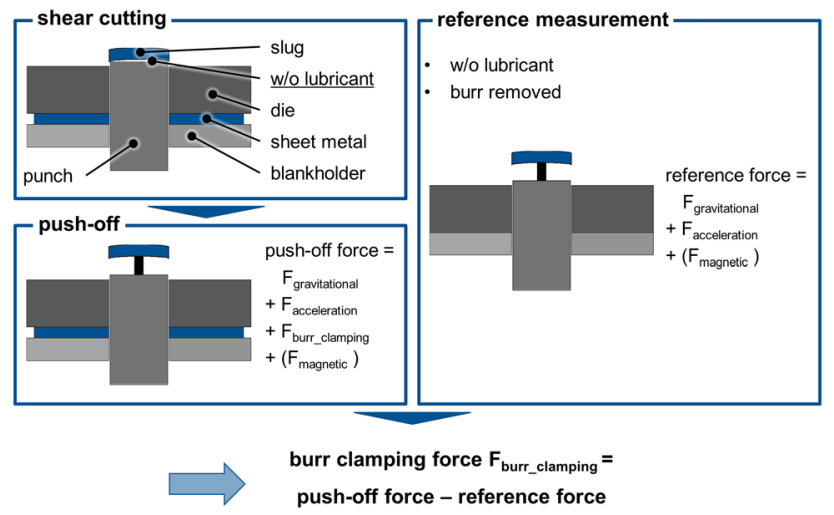

Fig. 9 Procedure for determining the burr clamping force

\subsubsection{Results}

In Fig. 10, the burr clamping force is presented for punch diameters of $10 \mathrm{~mm}$ and $20 \mathrm{~mm}$ depending on the relative die clearance. This shows that the punch diameter has a considerable influence on the burr clamping force since the burr clamping force with a small punch diameter of $10 \mathrm{~mm}$ is approx. $70-90 \%$ less compared to a punch diameter of $20 \mathrm{~mm}$ depending on the die clearance. The higher burr clamping force with larger punch diameters is attributed to the larger punch circumference, as this force acts on the punch's shape. However, based on the available data, no linear relationship between circumference and burr clamping force can be determined. The reason for the relatively large spread of the burr clamping force with a punch diameter of $20 \mathrm{~mm}$ is seen in the heterogeneous accelerations of the punch during the cutting stroke. Depending on the severity of the cutting stroke, acceleration forces of different strengths act on the slug, which can already partially loosen or detach from the face. Since larger punch diameters result in higher cutting forces and thus more potential energy is

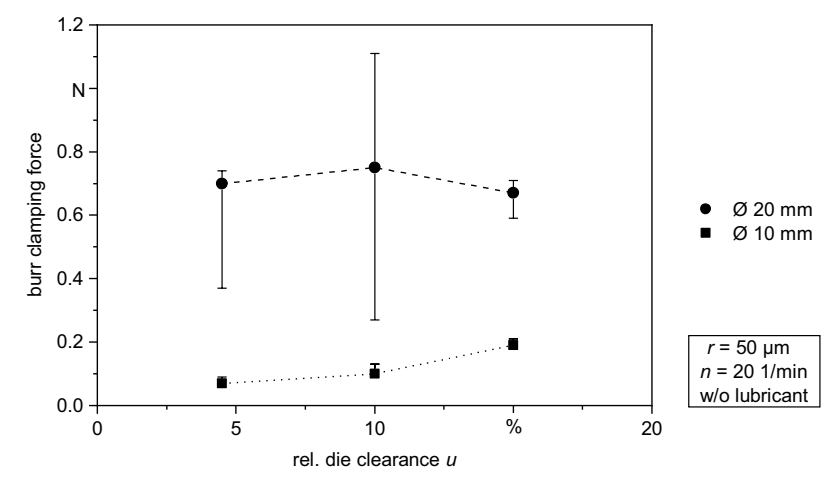

Fig. 10 Punch diameter influence on the burr clamping force for different die clearances

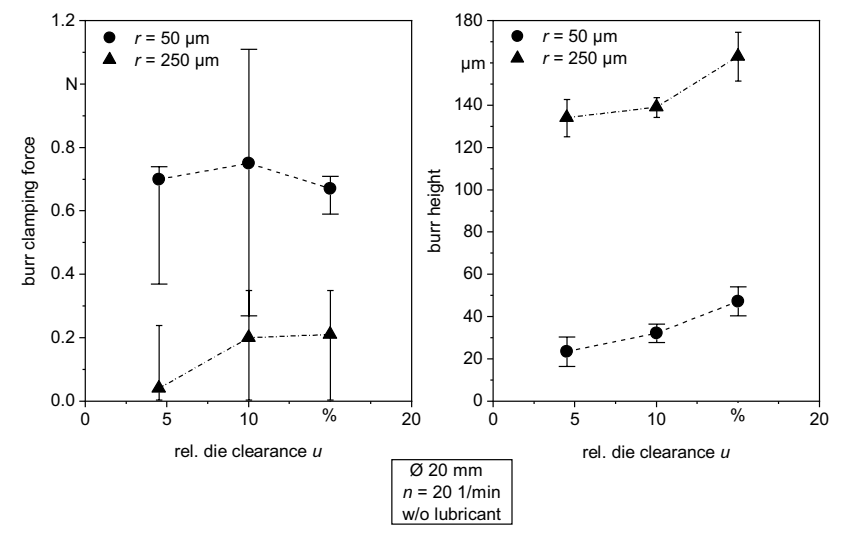

Fig. 11 Influence of the cutting edge radius on the burr clamping force and comparison with the corresponding burr heights

stored in the system before the sheet metal breakthrough, stronger cutting strokes are to be expected here.

The influence of the cutting edge radius on the burr clamping force is shown in Fig. 11 for different relative die clearances. Here, a sharper-edged punch with an edge radius of $50 \mu \mathrm{m}$ exhibits significantly higher burr clamping forces compared to a cutting edge radius of $250 \mu \mathrm{m}$. This is remarkable, since the larger edge radius causes higher burrs on the slug (see Fig. 11, right side). Thus, no direct correlation between the height of the burr and the force due to burr clamping can be detected. It is assumed that in addition to the slug diameter, an interaction of the burr height, the cutting edge geometry, the slug spring back, the slug stiffness and the coefficient of friction between the slug and the punch is responsible for the resulting burr clamping force. However, further research is necessary on this topic.

In Fig. 11 (left side) a relatively wide spread of the measured burr clamping force is notable. This is attributed to heterogeneous accelerations of the punch during the cutting stroke as described previously. Therefore, in the experiments with a cutting edge radius of $250 \mu \mathrm{m}$, sometimes no more burr clamping force can be measured because the slug has already detached from the punch's front face before the push-off process happens.

\subsection{Adhesive force}

\subsubsection{Test execution and evaluation}

The adhesive force is determined in a similar way as the burr clamping force. After shear cutting, the slug is pushed-off the punch's front face and the push-off force is measured. In contrast to measurements of the burr clamping force, the shear cutting and push-off tests are carried out with the use of lubricant. The lubricant is applied by hand to the previously cleaned and degreased sample. Here, a uniform 


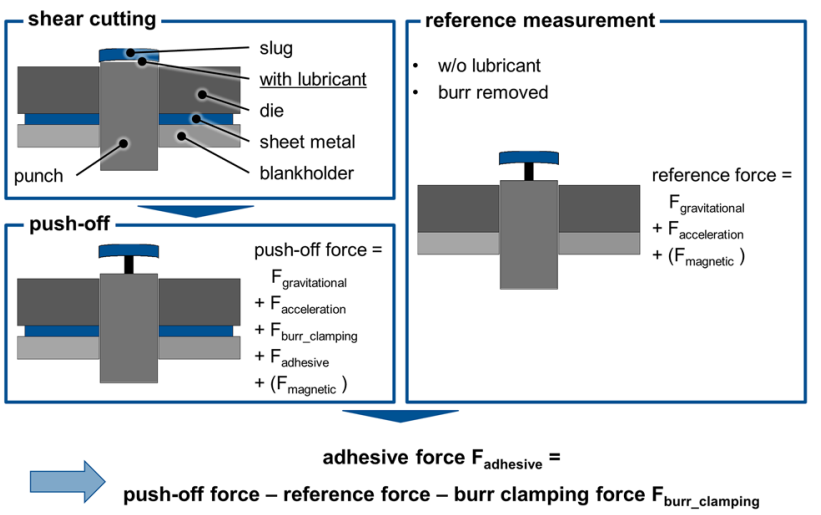

Fig. 12 Procedure for determining the adhesive force

lubricant application is to be guaranteed by a standardized procedure. Thus, in addition to the gravitational force, the acceleration force, the burr clamping force and magnetic forces, the adhesive force is also part of the push-off force. The amount of the adhesive force is determined by subtracting the reference measurement and the median of the corresponding burr clamping force from the push-off force measurement, as presented in Fig. 12. In the following figures, the median value of the adhesive force is displayed. The error bar describes the range between the first and third quartiles.

\subsubsection{Results}

Figure 13 shows the influence of the lubrication on the adhesive force depending on the relative die clearance. Here lubricant 1 with the higher viscosity causes larger adhesive forces than the lower viscosity lubricant 2 . It becomes apparent that negative adhesive forces are calculated for the lowviscosity lubricant 2 . This is because the use of lubricant affects not only the adhesive force, but also the burr clamping force, since the friction between the burr and the punch is reduced. If the reduction of the burr clamping force is

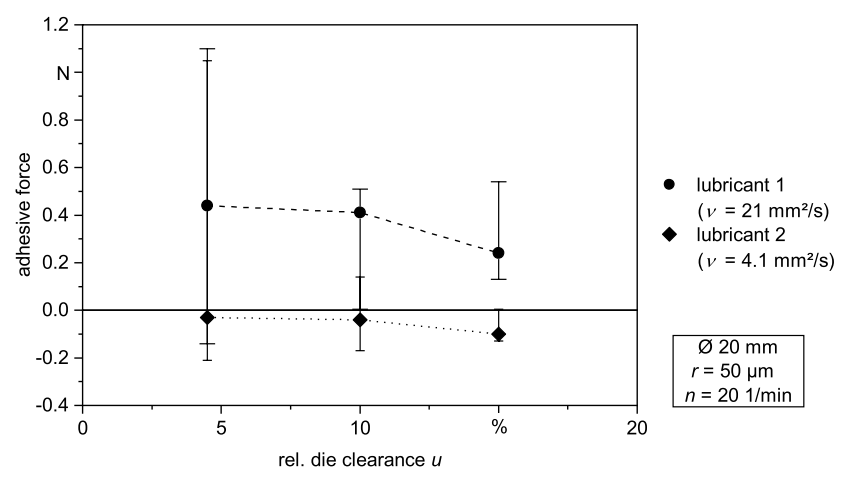

Fig. 13 Influence of the lubricant on the adhesive force for different die clearances

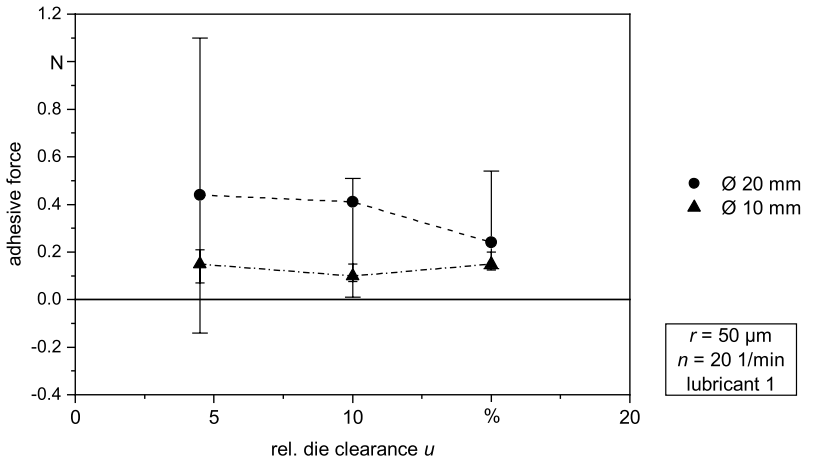

Fig. 14 Influence of the punch diameter on the adhesive force for different die clearances

greater than the magnitude of the adhesive force, this causes quasi-negative adhesive forces. Furthermore, the size of the error bar is very large, especially for the small die clearance. In addition to the heterogeneous acceleration forces during the cutting stroke, this is also attributed to imperfections in the manual lubrication. The effects are most distinct with the small die clearance, because here the deflection of the slug is the least due to the small lever arm while shear cutting. Thus, the oiled contact area between the slug and the punch's face is greatest here.

The influence of the punch diameter on the adhesive force for different die clearances is shown in Fig. 14. It can be seen that the smaller punch diameter of $10 \mathrm{~mm}$ causes lower adhesive forces than the punch with a $20 \mathrm{~mm}$ diameter. The higher adhesive force with a larger punch diameter is attributed to the larger oiled contact area between the punch's front face and the slug that can be found here.

\section{Discussion}

In order to select suitable remedial measures against slug pulling, it is essential to know the composition of the forces causing the slug pulling. This includes the three partial forces due to vacuum, burr clamping and adhesion. The composition for various cutting parameters is discussed below.

The relative composition of the forces that cause the slug to stick to the punch is presented in Fig. 15 as a function of two different punch diameters and three different die clearances $u$. The cutting edge radius $r=50 \mu \mathrm{m}$, the punch-penetration-depth $p p d=2.0 \mathrm{~mm}$, the stroke rate $n=20 \mathrm{1} / \mathrm{min}$ and the lubrication with lubricant 1 remain constant. Here, a larger die clearance causes the amount of the vacuum force to decrease. The amount of the burr clamping force increases, while the percentage amount of the adhesive force remains approximately the same for all three die clearances. Although a decrease in the amount of 


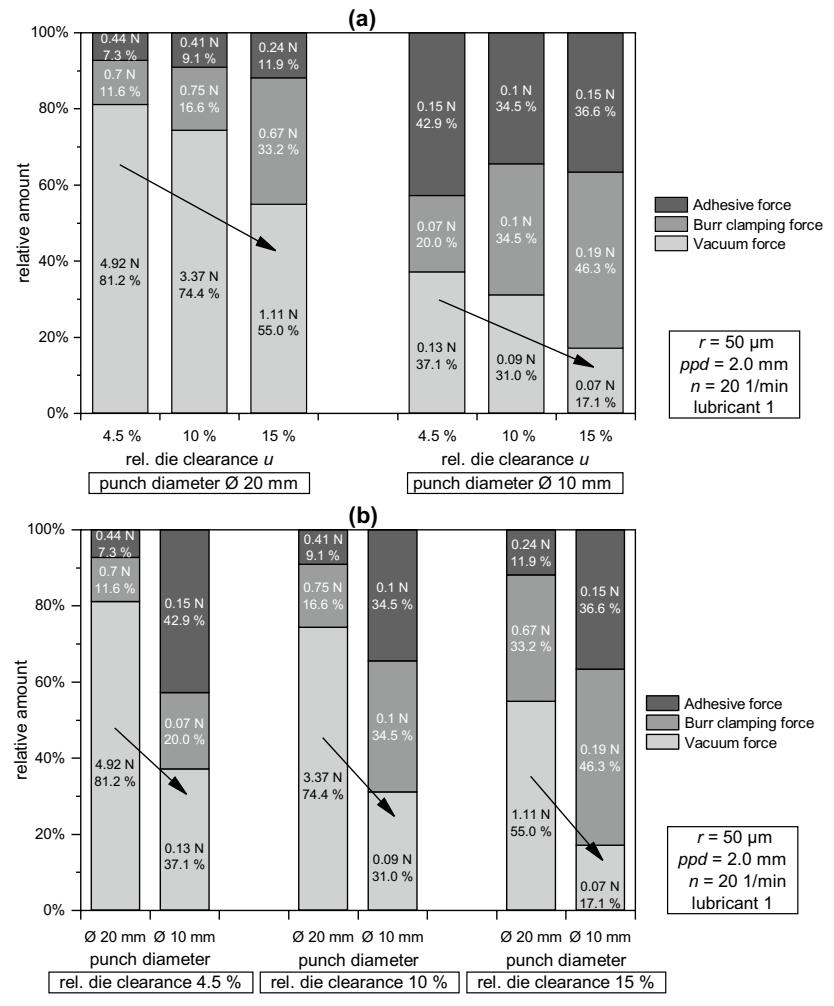

Fig. 15 a Distribution of the partial forces for two punch diameters depending on the die clearance; $\mathbf{b}$ distribution of the partial forces for three die clearances depending on the punch diameter

the vacuum force is found with larger die clearances, with a punch diameter of $20 \mathrm{~mm}$ and the largest die clearance of $15 \%$ the vacuum force is still the largest partial force that causes slug pulling (Fig. 15a). When using a smaller punch diameter of $10 \mathrm{~mm}$ compared to $20 \mathrm{~mm}$, the importance of the vacuum force decreases significantly. The consequence of this is that the amounts of the burr clamping force and the adhesive force increase. Accordingly, greater attention has to be paid to these two forces when using smaller punch diameters (Fig. 15b).

Figure 16 shows the influence of the punch-penetrationdepth into the die and the cutting edge radius on the distribution of the partial forces. The amount of the vacuum force increases with a larger punch-penetration-depth into the die, which means that the relevance of the burr clamping force and the adhesive force decreases. In addition, the amount of the burr clamping force decreases significantly with the larger cutting edge radius. As a result, the amounts of the vacuum force and the adhesive force increase, although these forces are only relatively slightly dependent on the cutting edge radius.

The influence of the lubrication on the partial forces is illustrated in Fig. 17, whereby the range between the first and the third quartiles is given for each partial force. It is recognizable that the lubrication has no noticeable influence on the vacuum

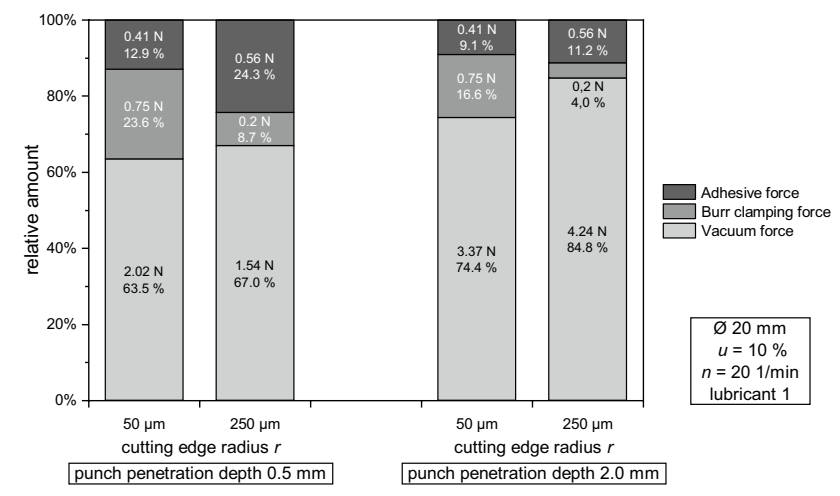

Fig. 16 Distribution of the partial forces depending on the punchpenetration-depth and the cutting edge radius

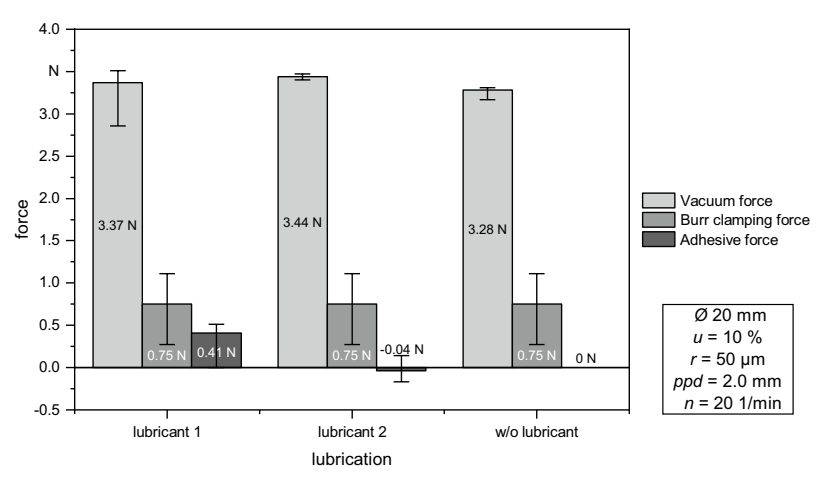

Fig. 17 Comparison of the partial forces and their spread at different lubrication conditions

force. By definition, the burr clamping force is also independent of the lubrication, since this force is always determined without the use of a lubricant. The low viscous lubricant 2 with a viscosity of $4.1 \mathrm{~mm}^{2} / \mathrm{s}$ causes a quasi-negative adhesive force, which can be attributed to the reduction in the burr clamping force due to a reduced coefficient of friction. This effect was explained in the previous chapter. When analysing the error bars, it can be seen that the range of the vacuum force is relatively low. One explanation for this is the independence of this force from the lubrication, which is why this possible source of error is eliminated. However, the error bars of the burr clamping force and the adhesive force are relatively large in relation to the median, but are each in the range $|\mathrm{F}|<0.5 \mathrm{~N}$.

\section{Conclusion}

In this paper, the forces that cause slug pulling were investigated and the influence of the relevant process parameters on the respective forces was explained. Following, the proportionate distribution of the three forces vacuum force, burr clamping force and adhesive force was discussed for 
different selected combinations of shear cutting parameters. It could be found that the vacuum force is the dominant force that can cause slug pulling for the large punch diameter of $20 \mathrm{~mm}$. In addition to the punch diameter, the vacuum force is essentially dependent on the die clearance, the punch-penetration-depth and the cutting speed.

With the smaller punch diameter of $10 \mathrm{~mm}$, however, the proportion of the vacuum force is no longer dominant and the three forces are-depending on the selected process parameters-of approximately the same significance. The burr clamping force is significantly influenced by the punch diameter and the cutting edge radius, whereby this force is larger with a smaller radius. The magnitude of the adhesive force is also affected by the punch diameter. In addition, the viscosity of the lubricant is of importance since more viscous lubricant causes higher adhesive forces. In this context, the influence of the temperature in the production process could also be taken into account for future work, since with an increase in temperature, a decrease in viscosity and thus a reduction of the adhesive force can be expected.

In order to evaluate the risk of slug pulling, it is necessary to consider not only the forces that cause slug sticking, but also the forces that lead to a removal of the slug from the punch. Here, in addition to forces that act due to special remedial measures in the tool such as ejector pins or air blasts, the frictional force between the slug and the die or forces on the slug due to vibrations in the tool are of great importance. The results presented in this paper on the level and distribution of the forces that cause slug sticking are intended to create a basis for making decisions when selecting and interpreting remedial measures.

For future work, the influence and characteristics of the magnetic force when shear cutting steel materials should also be examined. In particular the treatment of the active elements, but also the progress of the magnetic force on the number of strokes should be determined in continuous stroke tests.

Acknowledgements The results in this work were performed on the research project EFB 10/213 (AiF $18440 \mathrm{~N}$ ) "Ursache und Vorhersage von hochkommenden Stanzbutzen" [Cause and prediction of slug pulling], which is sponsored by the European research association for sheet metal working (EFB) and the German federation of industrial research association (AiF)

Author contributions AK: investigations, methodology, writing-original draft, writing — review and editing, project administration. AS: investigations, validation, review and editing. JS: tool design, review and editing. IP: tool design. AN: tool design. RG: supervision. WV: supervision, funding administration.

Funding Open Access funding enabled and organized by Projekt DEAL.

Availability of data and material On request from the corresponding author.

\section{Declarations}

Conflict of interest The author declare that there is no competing interest.

Open Access This article is licensed under a Creative Commons Attribution 4.0 International License, which permits use, sharing, adaptation, distribution and reproduction in any medium or format, as long as you give appropriate credit to the original author(s) and the source, provide a link to the Creative Commons licence, and indicate if changes were made. The images or other third party material in this article are included in the article's Creative Commons licence, unless indicated otherwise in a credit line to the material. If material is not included in the article's Creative Commons licence and your intended use is not permitted by statutory regulation or exceeds the permitted use, you will need to obtain permission directly from the copyright holder. To view a copy of this licence, visit http://creativecommons.org/licenses/by/4.0/.

\section{References}

1. DIN 8588:2013-08 (2013) Manufacturing processes severingclassification, subdivision, terms and definitions. DIN Deutsches Institut für Normung e. V., Beuth, Berlin

2. Volk W, Stahl J (2015) Shear Cutting. In: The International Academy for Production Engineering et al (eds) CIRP encyclopaedia of production engineering. Springer, Berlin. https://doi.org/10.1007/ 978-3-642-35950-7_16823-1

3. Schmidt R-A, Birzer F, Höfel P, Hellmann M, Reh B, Rademacher P, Hoffmann H (2007) Cold forming and fineblanking. Carl Hanser, Munich

4. Senn S, Liewald M (2018) Numerical investigation of a new sheet metal shear cutting tool design to increase the part quality by superposed compression stress. In: Journal of Physics, Conf. Series 1063. IOP Publishing, Bristol. https://doi.org/10.1088/ 1742-6596/1063/1/012181

5. Senn S, Liewald M (2019) A method for producing burr-free shearing surfaces to increase part quality through two-stage counter-cutting. AIP Conf Proc. https://doi.org/10.1063/1.51126 22

6. Feistle M, Pätzold I, Golle R, Volk W, Frehn A, Ilskens R (2018) Maximizing the expansion ratio through multi-stage shear-cutting process during collar forming. In: Materials science and engineering, conf. series 418. IOP Publishing, Bristol. https://doi.org/10. 1088/1757-899X/418/1/012071

7. Mucha J, Jaworski J (2016) The tool surface wear during the silicon steel sheets blanking process. Mainten Reliab 18(3):332-342. https://doi.org/10.1753/ein.2016.3.3

8. Hohmann J, Schatz T, Groche P (2017) Intelligent wear identification based on sensory inline information for a stamping process. In: Proceedings of 5th international conference on advanced manufacturing engineering and technologies. Springer, Berlin, pp 285-295. https://doi.org/10.1007/978-3-319-56430-2

9. Niederhofer P, Eger K, Schwingenschlögel P, Merklein M (2020) Properties of tool steels for application in hot stamping. Steel Res Int. https://doi.org/10.1002/srin.201900422

10. Cora ÖN, Koc M (2018) Wear resistance evaluation of hard-coatings for sheet blanking die. Procedia Manuf 15:590-596

11. Subramonian S, Altan T, Ciocirlan B, Campbell C (2013) Optimum selection of variable punch-die clearance to improve tool life in blanking non-symmetric shapes. Int J Mach Tools Manuf 75:63-71 
12. Abe Y, Yonekawa R, Sedoguchi K, Mori KI (2018) Shearing of ultra-high strength steel sheets with step punch. Procedia Manuf 15:597-604

13. Hedrick A (2004) Tackling cutting and piercing problems in stamping operations. Stamp J. https://www.thefabricator.com/ stampingjournal/article/stamping/tackling-cutting-and-piercingproblems-in-stamping-operations. Accessed 16 Feb 2021

14. Hedrick A. (2005) Solving pierce punch breaking and chipping problems. Stamp J. https://www.thefabricator.com/stampingjo urnal/article/punching/solving-pierce-punch-breaking-and-chipp ing-problems. Accessed 16 Feb 2021

15. Krinninger M, Steinlehner F, Opritescu D, Golle R, Volk W (2017) On the influence of different parameters on the characteristic cutting surface when shear cutting aluminum. Procedia CIRP 63:230-235

16. Tittel V, Bernadic L (2012) A review of methods and precautions against slug pulling. Int J Pure Appl Sci Technol 12(1):7-15

17. Strasser F (1963) Stanzereitechnik: Wie vermeidet man das Hochkommen von Butzen und Ausschnitten? Werkstatt und Betrieb 96(5):319-320

18. Patnaik L, Maity SR, Kumar S (2019) A review on slug reversal during punching and blanking. Mater Today Proc 18:2745-2752

19. Hsu RQ, Chang JR, Liang DL (2008) Prediction of slug carry-up by the punch in blanking by air-blow of the slug. J Mater Process Technol 201:252-255
20. Dannenmann E, Sugondo S (1981) On the adhesion of blanks to the punch in blanking and piercing. CIRP Ann 1981 Manuf Technol 30(1):167-170

21. VDI 2906:1994-05 (1994) Quality of cut faces of (sheet) metal parts after cutting, blanking, trimming or piercing. VDI-Gesellschaft Produktion und Logistik, Beuth, Düsseldorf

22. Mahr (not dated) Technische Daten-Konturenvorschubgerät PCV. Mahr GmbH, Göttingen

23. Thyssenkrupp (2018) Deep-drawing steels DD, DC and DX. thyssenkrupp Steel Europe AG, Duisburg. https://www.thyssenkruppsteel.com/media/content_1/publikationen/produktinformationen/ dd_dx_dc/thyssenkrupp_dd-dc-dx_product_information_steel_en. pdf. Accessed 16 Feb 2021

24. Romanowski W (1979) Directory on cold forging (Russian version: Spravochnik po holodnoj shtampovke), 6th edn. "Engineering" ("Mashinostroenie"), Leningrad

25. Canti R (2016) Analyse für eine belastungs-gerechte Auslegung von Presswerkzeugen am Beispiel Niederhalter und Schiebersystem. Dissertation, Technical University of Munich

Publisher's Note Springer Nature remains neutral with regard to jurisdictional claims in published maps and institutional affiliations. 